\title{
Mental Disorders and Consumption of Psychoactive Substances in Women: Epidemiological and Clinical Aspects in the Service of Psychiatry of the Donka National Hospital Guinea, Conakry
}

\author{
Keita $M M^{1 *}$, Doukouré $M^{2}$, Condé $S^{3}$, Soumaoro $K^{4}$ and Souare $M^{5}$ \\ ${ }^{1}$ Psychiatrist-addictologist, Psychiatric Department of Donka National Hospital, Conakry University Hospital \\ ${ }^{2}$ Child Psychiatrist, Psychiatric Service of Donka National Hospital, CHU Conakry \\ ${ }^{3}$ Psychiatrist, Department of Psychiatry at Donka National Hospital, CHU Conakry \\ ${ }^{4}$ Psychiatrist, Department of Psychiatry at Donka National Hospital, CHU Conakry \\ ${ }^{5}$ Psychiatric Department of Donka National Hospital, CHU Conakry
}

*Corresponding Author: Dr. Keita MM, Psychiatrist-addictologist, Psychiatric Department of Donka National Hospital, Conakry University Hospital, Conakry, Guinea; Tel: 224628779717 (or) 657408760; Email: saramady1957@gmail.com (or) keitapsy@yahoo.fr

Received: 29 January 2018; Accepted: 26 February 2018; Published: 02 March 2018

\begin{abstract}
Introduction: The use of psychoactive substances (PPS) is a public health problem for vulnerable populations, particularly women and those with mental disorders.

Objectives: In this work, our objectives were to determine the frequency of mental disorders and consumption of psychoactive substances in women, to describe their socio-demographic profile, to identify the psychoactive substances consumed, to identify the different types of mental disorders and to describe the clinical aspects of mental disorders induced by the consumption of psychoactive substances in these women.

Methodology: This was a retrospective study, of a descriptive type with a duration of 5 years (from 1 January 2009 to 31 December 2013). Data collection lasted three months. Included in this study were all records of hospitalized or outpatient patients in the Mental Disorders and Psychoactive Substance Use Service.

Results: The incidence of mental disorders and psychoactive substance use was $10.51 \%$. The age groups $20-29,30-$ 39 were the most represented are respectively $55.49 \%, 31.87 \%$ with an average age of 29.5 years and extremes of 10-49 years. Singles were the most affected with $91.76 \%$ of cases. The majority was in the informal sector and the secondary level was the most affected with $40.11 \%, 56.04 \%$, respectively. The most commonly used psychoactive
\end{abstract}


substances were cigarettes (3.30\%) and alcohol (2.20\%). The alcohol and cigarette association was the most frequent, $45.60 \%$. Depression was the most prevalent type of disorder with $35.71 \%$. Occasional consumption was the most common mode of consumption with $84.62 \%$, followed by $15.38 \%$ of regular consumption or dependence.

Conclusion: This retrospective study did not identify all aspects of women's psychoactive substance use, yet a general population survey could better capture the magnitude of this phenomenon.

Keywords: Guinea (Conakry); Women; Psychoactive substances; Mental disorders; Epidemiology; Clinic

\section{Introduction}

Mental disorders are clinical conditions characterized by a change in thinking, mood and behavior [1]. According to the WHO, "a psychoactive substance (PPS)" refers to a substance that is ingested or administered, which impairs mental processes such as cognitive function or affect [1]. The links between mental disorders and psychoactive substance use are not straightforward. In part, mental disorders may be risk factors for increased use of psychoactive substances and, secondly, psychoactive substance abuse may be a risk factor for mental disorders [2]. With regard to gender, it is clear that consumption data indicate a difference between men and women. Regardless of the product and mode of consumption, women consume less than men. This gap in addictive behaviors between men and women often tends to ignore feminine addiction as more and more people develop their own forms of addiction [3]. The consumption of this product is not a problem of society, not only because of the misuse of this product, but also because of the negative consequences that the traffic and the use of these substances induce in economic terms, sanitary, social and mental. The studies conducted by (SERGE and GUILLAUME) [4], note a coexistence between mental problems and substance abuse, particularly among women who have suffered violence during childhood.

In France, BECK's work indicates that women in high socioeconomic positions tend to drink more than women in less advantaged positions [5]. If women remain a minority among cannabis smokers (5\% of women against $23 \%$ of men), they catch up with men in terms of tobacco (27\% for them against $33 \%$ for them), and ahead of them in consumption psychotropic drugs (23\% versus 13\%) [3]. In GUINEA, Doukouré M et al. [6] in their study of psychoactive substances and mental disorders reported a 5\% frequency of psychoactive substance use among women. The use of PPS and drug addiction among women are constantly increasing in Guinea, they have become a real public health problem, they are the worst scourge of our time, because it affects young people at an older age. earlier and destroys the vital force of our country. It is a terrible threat to the future of our society. Yet despite this critical situation, women as such are of little interest to investigators. The absence of a previous study on mental disorders and psychoactive substance use among women in Guinea motivated the choice of this theme.

Our objectives for this study were to determine the frequency of mental disorders among women who use psychoactive substances and to describe their socio-demographic profile, to identify the psychoactive substances they use, to identify the different types of mental disorders and to describe the clinical aspects. Mental disorders induced by the consumption of psychoactive substances. 


\section{Methodology}

The psychiatric service of Donka National Hospital served as the framework for the realization of our study. It is the only reference center in the country for the management of mental disorders, behavior and addictions to psychoactive substances. The study looked at the records of patients in hospital or outpatients in the department who had mental health disorders with substance use during the study period. We used as support for data collection, consultation and hospitalization records, patients' individual files and an investigation form developed for this purpose. This was a retrospective, descriptive study lasting five years (from January 1, 2009 to December 31, 2013). Data collection lasted three months. Our study population consisted of patient records received in the department, hospitalized or followed as outpatients for mental disorders and PPS consumption during the study period. Included in our study were all records of patients hospitalized or followed as outpatients in the department during the study period in which the diagnosis of mental disorders and consumption of one or more psychoactive substances was retained and whose records included the parameters of our study; however, incomplete patient records received in the department during the study period and for other diagnoses than mental disorders and ASA were excluded from this study. We grouped our variables into quantitative and qualitative variables to allow an analysis of our data. The anonymity was preserved and the survey cards were destroyed after the study. As with any scientific study, we have been faced with certain difficulties, including the incomplete filling of some medical files and the lack of similar studies carried out on this subject in the Service.

\section{Results}

The frequency of mental disorders and substance use was $10.51 \%$. The age groups 20-29, 30-39 were the most represented being respectively $55.49 \%, 31.87 \%$ with an average age of 29.5 years and extremes of 10-49 years. Singles were the most affected with $91.76 \%$ of cases. The majority was in the informal sector and the secondary level was the most affected, with $40.11 \%$ and $56.04 \%$ respectively. The most used psychoactive substances were cigarettes (3.30\%) and alcohol (2.20\%). The association alcohol and cigarette was the most frequent is $45,60 \%$. Depression was the most predominant type of disorder with $35.71 \%$. Occasional consumption was the most popular mode of consumption with $84.62 \%$, followed by $15.38 \%$ of regular consumption or dependence (Table 1 ).

\begin{tabular}{|c|c|c|}
\hline Consumed substances & Number of cases & Percentage \\
\hline Cigarette only & 6 & 3.30 \\
\hline Palm wine alone & 2 & 1.10 \\
\hline Alcohol alone & 4 & 2.20 \\
\hline Alcohol + Cigarette & 83 & 45.60 \\
\hline Cannabis + Alcohol + Cigarette & 76 & 41.76 \\
\hline Cannabis + Alcohol + Alcohol + Cigarette & 2 & 1.10 \\
\hline Cannabis + Alcohol & 8 & 4.40 \\
\hline Tea + Benzodiazepine & 1 & 0.55 \\
\hline Total & 182 & 100 \\
\hline
\end{tabular}

Table 1: Distribution of patients by substances consumed. 


\section{Discussion}

The main difficulty of our study was the lack of specific documentation concerning mental disorders and consumption of PPS in women elsewhere and in Guinea, nevertheless we reached the following results:

During the study period, 1732 patients were received in consultation, of which 182 patients presented with mental disorders and psychoactive substance use, with a hospital frequency of $10.51 \%$ (Figure 1).

In 2007 Doukouré et al. [6] found a 5\% incidence of mental disorders related to substance use among women.

In Quebec Serge Brochir et al. Found in their study of substance use among female prisoners a frequency of $94.7 \%$ [7].

This low incidence of women with mental disorders and psychoactive substance use in our study may be due to the fear of being judged, they have a much harder time getting through the door of a health center. especially psychiatric that men and on the other hand, they are victims of double punishment, shame and guilt, because our society still very severely judges these women. Feeling ashamed, delay their consultation and necessarily their treatment and prefer a self-therapy.

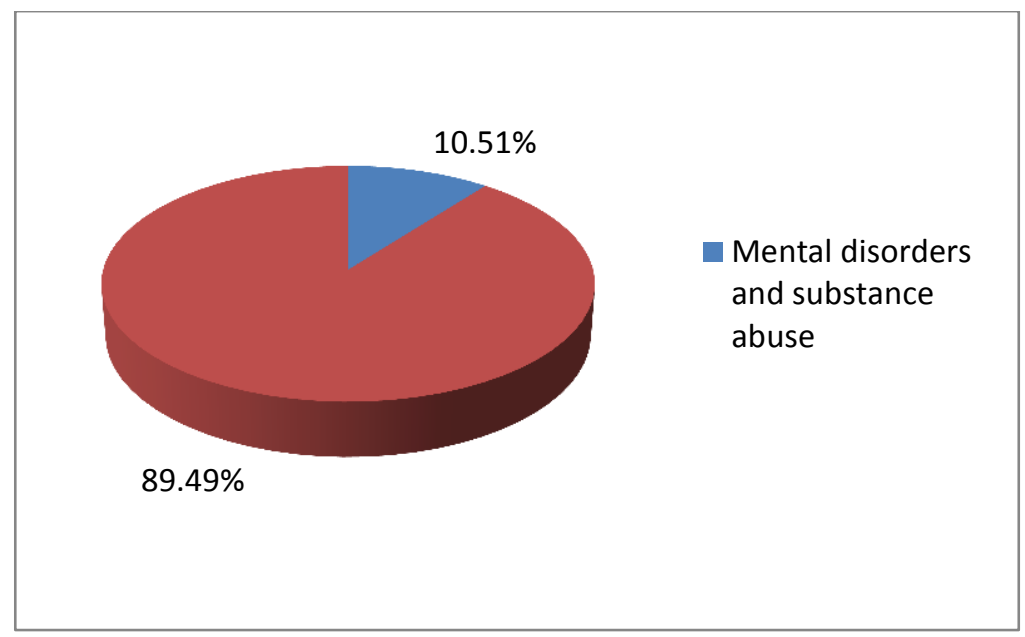

Figure 1: Frequency of mental disorders and psychoactive substance use among women.

The age of the patients varies between 10 to 49 years with an average of 29.5 years. The most affected age groups were $20-29$ years old, $30-39$ years old respectively $55.49 \%$ and $31.87 \%$. This predominance of young adults could be explained by the fact that these periods constitute the transition between childhood and adulthood and are periods of high psychological vulnerability, instability of the personality in women as well, the consumption of some psychoactive substances can trigger mental disorders, and the older women become, the more it turns out that substance use is shifting to so-called hard drugs (such as hallucinogens, cocaine and heroin). Subsequently, the experimentation of new products is more rare and one observes a certain stability inside the drugs already experimented. However, the feminization of the consumption phenomenon remains a current concern. These results confirm those reported by Biron and Savard [8]. In the vast majority of cases, the association alcohol and cigarettes (45.60\%), cannabis, alcohol and cigarette $(41.76 \%)$, was the most observed. This high frequency of psychoactive 
substance use could be explained on the one hand by their easy accessibility and at a lower cost and on the other hand, the consumption of these psychoactive substances could reduce social inhibitions, occupational stress and increases sensations, desire, excitement as well as sexual pleasure, the notion of climbing and the search for sensation [9] (Figure 2).

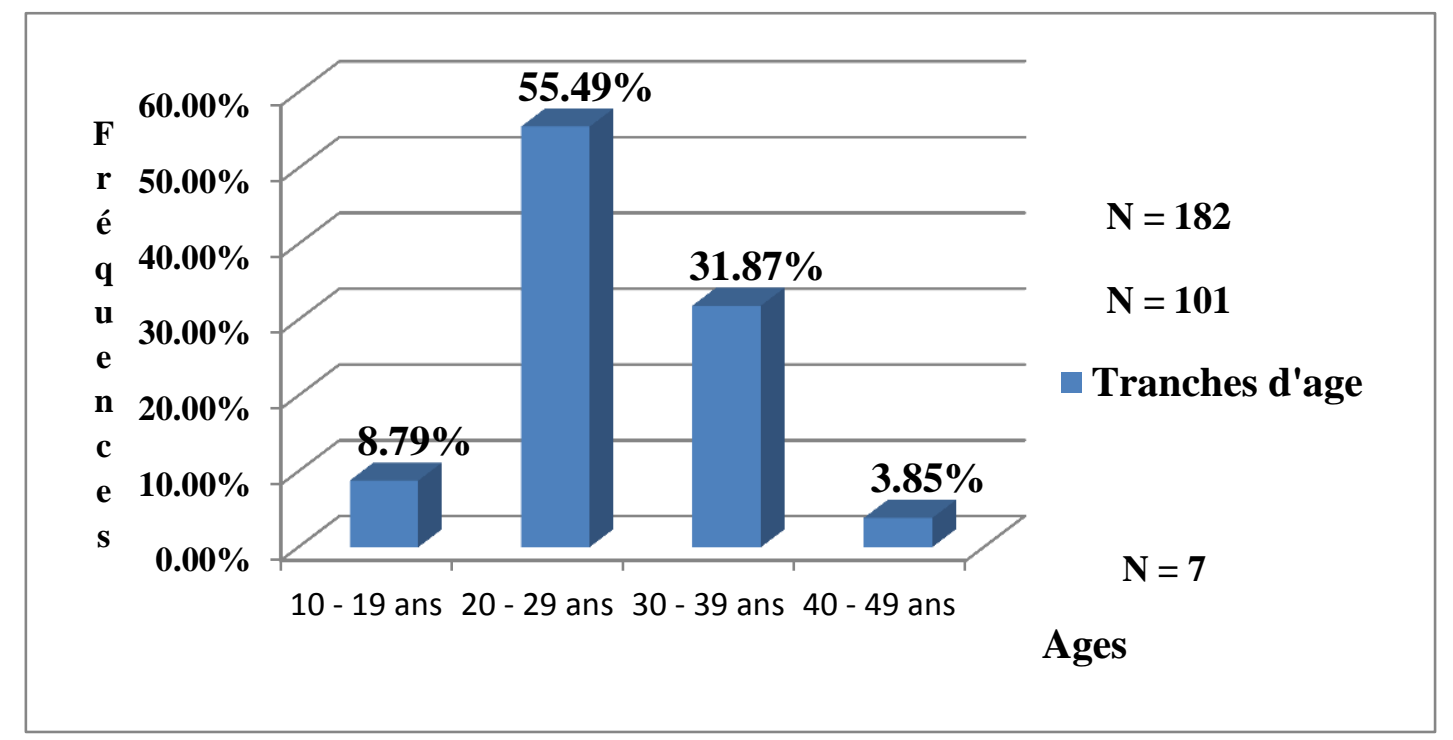

Figure 2: Distribution of patients by age. Average age: 29.5 years. Extreme ages: 10-49 years.

The vast majority (91.76\%) are single people versus (2.75\%) brides. Unlike our study, Verdoux H and al. reported $47.5 \%$ of brides [10] who had mood disorders associated with substance use. This high frequency of singles could be explained by the fact that they are young people in whom the mental disorders and behavior engendered or aggravated by the consumption of psychoactive substances compromise any marriage project, but also disrupts the socio-occupational functioning and family of these subjects. The vast majority of the study population (56.04\%) has a secondary level followed by a primary level (32.97\%). This high level of secondary education can be explained by the fact that these are teenage girls, who for the most part make their first experiences of using psychoactive substances, either out of curiosity, during festivities or through their friends; which, in the long run, decreases school performance and then leads to a cessation of schooling. This rate of $32.97 \%$ for the primary level draws attention to the precocity of the phenomenon in preadolescent women. Weiss and Michel G reported in their study that most patients with mood disorders associated with substance use had a low academic level [11, 12].

In our study the informal sector was the most affected with $40.11 \%$ of cases followed by formal training $28.57 \%$. This high frequency of patients in the informal sector could be explained by the fact that hard work in this sector most often requires the use of psychoactive substances to fight or resist fatigue. Formal training, usually involving adolescent girls and young adults, is a source of stress and frustration. Generally, young students consume these psychoactive substances to fight against stress, but also try the drug out of curiosity, fashion, the pressure of the group, the fascination of the taboo, just as to flee suffering and loneliness. Okitundu and al. found that most patients in their series were from the informal sector [13]. The vast majority of the study population (84.62\%) had a simple use against $15.38 \%$ of cases of dependence. This high frequency of simple use could be explained by the fact that 
most women consume during the holidays, a dance party for the search for a new sensation. There is, however, the speed of installation of dependence on certain psychoactive substances in women such as alcohol, tobacco, cannabis, etc. The most commonly observed mental disorders were mood disorders (depression, bipolar disorder, mania), respectively $(35.71 \%, 27.47 \%, 22.53 \%)$ (Table 2 and 3$)$.

\begin{tabular}{|c|c|c|}
\hline Terms of use & Number of cases & Percentage \\
\hline Outbuilding & 28 & 15.38 \\
\hline Simple use & 154 & 84.62 \\
\hline Total & 182 & 100 \\
\hline
\end{tabular}

Table 2: Distribution of patients according to consumption patterns.

\begin{tabular}{|c|c|c|}
\hline Mental disorders and substance use & Number of cases & Percentage \\
\hline Delirious puff & 20 & 10.99 \\
\hline Dépression & 65 & 1.10 \\
\hline Schizophrenia & 21 & 22.53 \\
\hline Manic access & 3 & 1.65 \\
\hline Pathological intoxication & 50 & 27.47 \\
\hline Bipolar disorders & 1 & 0.55 \\
\hline Chronic Hallucinatory Psychosis & 182 & 100 \\
\hline Total & & \\
\hline
\end{tabular}

Table 3: Distribution of Patients by Mental Disorders and Consumption of psychoactive substances.

This could be explained by the fact that mood disorders are providers of psychoactive substance use. Our result is clearly superior to the result of Bastin $\mathrm{P}$ et al. who found that $70 \%$ of the maniacs used psychoactive substances [14]. The majority of our patients were hospitalized $56.04 \%$ against $43.96 \%$ of ambulatory follow-up. This high frequency of cases of hospitalization is explained by the fact that the behavioral disorders caused by different psychoactive substances disturb not only the socio-professional functioning of the patient, her family balance, but also the socio-cultural intolerance of consumption. psychoactive substances in women, which indicates their management in hospitalization. The most predominant reasons for consultation were insomnia (100\%), psychomotor retardation $(89.01 \%)$, moodiness $(60.44 \%)$ followed by headache $(52.75 \%)$, logorrhea (48.35\%), ambulation $(43.41 \%)$, psychomotor agitation $(45.05 \%)$. Our data are consistent with those in the literature [14, 15] regarding the prevalence of these different symptoms in mental disorders and substance use. The explanation that could be given for these psychiatric manifestations is the acute or chronic effect of drugs, which have a common characteristic on the central nervous system. 


\section{Conclusion}

Mental disorders and psychoactive substance use among women occupy an important place among psychiatric pathologies. Their epidemiological and clinical study is complex, it involves several factors including age, occupation, associations of toxic, lifestyle, symptoms. We found in our study that adolescent girls and young adult women were the most affected with a clear predominance of single people. The majority evolved in the informal sector. Many of our patients had a level of study. The secondary level was the most affected, but the $32.97 \%$ of the primary level should draw attention to the early and rejuvenated use of psychoactive substances.

This study also shows a predominance of the association of psychoactive substances. Alcohol and cigarettes were the most abused substances, followed by cannabis, alcohol and cigarettes. The most common mental disorders were bipolar disorder, manic access, depression and delirium. Occasional consumption was the most predominant type of consumption. The primary reasons for consultation were insomnia, mood exaltation, logorrhea, ambulation, psychomotor agitation, inconsistent speech, and moodiness. An extended study to the Guinean population on this question would be necessary to appreciate the extent of this phenomenon.

\section{References}

1. WHO. International classification of diseases, mental disorders and behavioral disorders. Clinical Descriptions and Guidelines for Tenth ICD-10 Diagnosis). Paris: House (1993).

2. Health Canada, Best Practices. Concurrent Mental Health and Substance Use Disorders.

3. Foundation between shame and guilt, women face their addictions (2012).

4. Serge Escots, Guillaume Suderie. Literature Review: Women and Addictions (2013): 7-10.

5. Beck F, Legleye S. Drugs and Adolescence, Drug Use and Contexts of Use at the End of Adolescence, Recent Developments, ESCAPAD 2002, France, Paris, OFDT (2003).

6. Doukouré M, Samoura M. Psychoactive Substances and Mental Disorders: Ph.D. Thesis in Medicine at the Psychiatry Department of Donka Hospital, Conakry, Guinea (2007): 9.

7. Brochu S, Biron L, Desjardins L. The consumption of psychoactive substances among women detained in Quebec.

8. Biron L, Savard C. Women who commit serious crimes. Ottawa, Solicitor General of Canada (1986): 16.

9. Frohmader KS, Pitchers KK, Balfour ME, et al. Mixing pleasures: review of the effects of drugs on hormone and human behavior hormones and Behavior 58 (2010): 149-162.

10. Verdoux H, Coll. Comparative study of addictive behavior in bipolar, schizophrenic and schizoaffective disorders, encephalon 22 (1996): 95-101.

11. Weiss RS, Ostacher MJ, Otto, et al. RECOVERY from substance use discord? Jclin Psychiatry 66 (2005): 730-735.

12. Michel G, Coll. Depressive symptomatology and psychoactive substance use in high school students, neuropsychiatrist, adolescent children 46 (1998): 531-536.

13. Okitundu L, Minfundu E-A. Cannabism and mental disorders in rural Zaire: Epidemiological aspects. Medicine of Black Africa 42 (1995): 243-245. 
14. Laurentk Michel R. Cognitive disorders and chronic use of cannabis. Ann Med. Internal 154 (2003): 15581564.

15. Yuj, Wilifordwr. The Age of Non-alcoholic Alcohol, Smoking and Marijuana Use Patters: An Analysis of Drug Use in New York State. Int addict 27 (1992): 1313-1322.

Citation: Keita MM, Doukouré M, Condé S, Soumaoro K, Souare M. Mental Disorders and Consumption of Psychoactive Substances in Women: Epidemiological and Clinical Aspects in the Service of Psychiatry of the Donka National Hospital Guinea, Conakry. Journal of Psychiatry and Psychiatric Disorders 2 (2018): $41-48$.

(C) 9 BY $\begin{aligned} & \text { This article is an open access article distributed under the terms and conditions of the } \\ & \text { Creative Commons Attribution (CC-BY) license 4.0 }\end{aligned}$ 